\title{
Three Years of Networking: A Personal History of NIEPS
}

THÉRÈSE JACOBS, Prof. Dr. Co-ordinator of NIEPS (2000-2003), General Director, Centre for Population and Family Studies, CBGS, Brussels, Belgium

\begin{abstract}
The paper offers a short and personal review of the NIEPS project. It starts with the ambition of the European Community to develop a 'European research area'. The paper then presents the terms of reference of this thematic network, financed by the European Community under its fifth research framework. These objectives and the architecture of the project are excellent examples of building a European research area. The last part contains an assessment of the attainment of these objectives. The method is intuitive and highly personal. The paper does not summarize the main results of the project; instead it gives a personal account of what happened and what was retained.
\end{abstract}

In January 2004 the final financial settlements of NIEPS are nearly finished: a perfect context to look back and make a short history and even shorter assessment of the process. I am very grateful to our colleagues in the Finnish Population Institute because they gave us the opportunity to publish the results of this review.

\section{Towards a European research area}

In a communication from the Commission of the European communities to the council, the European Parliament, the Economic and Social committee and the committee of the regions (COM 2000,6) the Commission defines the challenges for the research policy in the $21^{\text {st }}$ Century. They start from the need for Europe to achieve successfully the transition to a knowledge-based economy. One of the key factors of success is to create a European research area. This idea encompasses in the first place "Networking of existing centres of excellence in Europe" (p. 8). Another feature of the idea is that "the European research system must be organized in such way as to preempt and take account of needs arising at the different stages of implementation of public policies: drafting, decision-taking, implementation, monitoring. Policy-makers must be able to draw on precise knowledge, which is as 
complete as possible and constantly updated and validated." ( p. 15) Further in this text, the Commission mentions the need for integration of the scientific communities of western and eastern Europe : "Improving the research capacities of the countries applying for accession and integrating their researchers in the European scientific community can help them to prepare for accession." (p. 18) And finally the text states that one of the instruments to reach this goal are: "structures and mechanisms of exchange of information and experience: working groups, networks of experts and operators."(p. 22)

Our proposal was submitted and accepted ${ }^{1}$ in the first call for proposals (1999) of the fifth EU-research framework, under the key action "Improving the socio-economic knowledge base"; it is characterized by most of the before mentioned aspects, although formulated a year earlier.

NIEPS (Network for Integrated European Population Studies) is meant to be a transnational thematic network; it is policy oriented, brings together scholars of Western European countries and of countries in transition and its core business is networking and exchange of information.

The network brings together researchers of 11 major national population institutes in Europe ${ }^{2}$. As stated in the terms of reference of the contract, NIEPS "will form an all-European platform, which aims at promoting a dialogue on policy relevant interactive domains of population and family dynamics on the one hand and socioeconomic processes on the other. "It is interesting to observe that the interaction between the network and the institutes is described in two ways. First it is mentioned that the co-operation may result in the development of similar research programs in each of the institutes, and second, these common research programs facilitate the building of common research activities. This increases the "analytical power of the research because of the opportunity to observe a higher variance in the determinants of the phenomena under investigation." In my view this is indeed a scientific argument to develop a European research area.

${ }^{1}$ Contract n ${ }^{\circ}$ HPSE-CT-1999-00005

2 The partners are: The Population and Family study centre (CBGS) (Co-ordinator); Bundesinstitut für Bevölkerungsforschung (BiB), Germany; Netherlands Interdisciplinary Demographic Institute (NIDI), the Netherlands; Istituto di Ricerche sulla Popolazione (IRP), Italy; Population Research Institute (PRI), Finland; Department of Demography and Geodemography (KDGD), Czech Republic; Institut für Demographie (IFD), Austria; Estonian Interuniversity Population Research Centre (EKDK), Estonia; Demographic Research Institute (DRI), Hungary; Centre of Demography (COD), Latvia; Institute of Statistics and Demography (ISD), Poland. 


\section{Methods of networking}

In the philosophy of NIEPS, a network should be an open place of discussion and a place for action. The discussion aspect allows the members to share their knowledge on a certain theme; the action aspect allows them to sense the willingness to commit to and the feasibility of a common project. Another very important aspect is that a division of labor was agreed upon that guarantee each member of the network a specific task to perform (cf. "workpackage"). Next, networking is in se a process that has to be opened up to external actors. And finally, the process character of the project is stressed: the tool of the management meeting after each workshop makes a feedback of current experiences into the project possible.

This philosophy was materialized in the structure of the project and in the reporting policy. The structure consists of a series of workshops. Each theme was first discussed in order to grasp the problem in all its relevant aspects; then a technical meeting dealt with research designs; a second workshop again was mainly dedicated to discussion. In this last workshop the theme was considered from the policy point of view and the proposals from the technical workshops were integrated in the final discussion. In order to pin down the most important ideas and reflections, executive reports had to be made after each workshop and a final synthesis monograph has to be produced by the consultants.

The first workshop was meant to undertake a retrospective and comparative analysis of demographic trends. It gave the occasion to invite external experts, who had to present a state-of-the art report at least on one major aspect of the theme under study. Furthermore the representatives of the institutes gave a review of their own research projects.

The in-between technical meeting was meant to perform an in-depth examination and critical evaluation of theoretical frameworks and research instruments currently used in the given domain and to prepare draft outlines of innovative frameworks for future comparative research for discussion in the second workshop.

Finally, the second workshop again was open to external experts and state-of-the art papers. Specific to this workshop was planned to be the discussion on the results of the technical meeting.

So far we discussed the proposed architecture of the project; we noted that this construct grasps the core of the EC research policy. The architecture corresponds to the choice of themes and, in more general terms, to the scientific aims of the network. 


\section{Core aspects of population in the 21 st century}

From a population studies perspective, the need for bringing family formation patterns into context was one of the principles guiding the design of the Family and Fertility Survey (FFS) program. This project covers 21 countries in Europe, Canada, the United States and New Zealand. The fieldwork was carried out in the 1990s (1989-1999). Respondents were men and women. Total sample size was almost 47,000 men and 96,000 women. The core theme of the questionnaire was a biographical (retrospective) approach to fertility, partnership and employment careers. And yet, this database has been exploited to study trends in fertility with only minor integration of the information on employment careers, of gender related issues and of issues related to the integration of migrants. The NIEPS has been launched to systematically overcome this weakness in the analysis of family formation dynamics.

The network members were convinced that the three main demographic phenomena that constitute population structure and population dynamics are intrinsically linked to each other. These are fertility, mortality and migration. Fertility depends on the patterns of family building (timing, mode), on the patterns of gender relations and on work patterns. Low mortality, especially in the higher age groups, results in the increase of life expectancy and in the same time, patterns of intergenerational solidarity are under pressure. Moreover, these mortality patterns generate typical age specific vulnerabilities. Migration, more specifically migration from abroad, sets the population and the system in a global context. Demographic phenomena in other countries interfere by the mechanism of migration. In order to understand this interplay it is important to look at the diversity in the population of newcomers and the way they are integrated. Thus, the second theme "Ageing, intergenerational solidarity and age-specific vulnerabilities" is closely linked to theme 1: "Family formation, gender relations and patterns of work" and to theme 3: "Demographic and cultural specificity and integration of migrants". Especially from a policy perspective, family formation and migration would be much less relevant societal and political topics in conditions of stable replacement fertility patterns.

An integrated perspective on classic demographic phenomena, in view of the promotion of 'sustainable population development and integrated population and development policies' needs an integrated research design. To develop this new idea on population studies was the very high challenge of NIEPS. 


\section{How successful was NIEPS in reaching these terms of reference?}

I will not try to summarize the results of all NIEPS activities. The executive reports and the publications with solicited and other papers are available from the member institutions. In the next few pages I try to remember what struck me during the workshops - a little bit helped by a rereading of the executive reports - and I try to compare with the terms of reference as stated above. This is not at all a systematic approach, it is much more an intuitive exercise.

First I give some reflections on the networking aspect of NIEPS. Did the network observe the network philosophy as described in the proposal? Then I reflect upon the degree of achievement of the major practical objective of the network: to design an integrative and policy sensitive research on population issues.

\section{Networking through six successful seminars}

The kick-off meeting took place in February 2000 in Brussels at the co-ordinator's institute (CBGS). Management points were discussed, especially in view of the standardization of the workshops and technical meetings.

The first workshop on 'Gender relations, family and work' took place in Czech Republic, September 2000 and the second in Belgium, December 2001. The technical meeting was held in Hungary. The network invited 11 experts to present a solicited paper and several researchers from the participating institutions presented their research work formally as well as informally.

In one way or another all papers and interventions deal with one single phenomenon: they try to explain the low and very low fertility patterns in most of the European countries and they hypothesize about the reasons why these low patterns differ in between these countries. Here, family policy, gender policy and combination policy comes into play.

Bringing experts from several countries together in one single discussion certainly gives a surplus value, even more since the analyses presented in most of the solicited papers were comparative. To compare fertility patterns in between countries and to link them with the specific political context always is fruitful and generates innovative knowledge. But to discuss the proposed explanations in a setting where political correctness is not a priority, is still more interesting.

An example is the very first paper presented in the first workshop. The author was Magritt Jensen and she dealt with "Childbearing in marriage and outside: from unity to gender divide". One of her hypotheses to understand different fertility patterns 
in Norway and Italy, is based on the concept of "shrinking fatherhood". She sees an evolution towards extramarital births and high partnership dissolution patterns, which goes parallel with increasing fertility level. It is suggested that highly secularized and desinstitutionalized gender relations and family patterns favor higher birth rates. In the author's interpretation, both phenomena reduce the impact of men in the decision making on children and therefore, fertility rates are higher in Norway. During the discussion it became clear that colleagues from Southern Europe did not share this logic. Not cultural processes in se, but economic constraints and a lack of family policy tools (childcare, parental leave) are the most important. They do not agree with a suggestion that the disappearance of the institution of marriage and the stability of personal relations per se generate higher fertility rates.

The participation of members of the countries in transition proves even more the importance of a heterogeneous network. I remember during the same workshop, when the relationship between fertility and work patterns was discussed that in several countries, notwithstanding an excellent infrastructure of childcare facilities, the fertility levels were in a free fall. The executive report states in academic wording: 'It was argued that the involvement of wider geographical perspective, including the developments in Central and Eastern Europe, might facilitate disentangling the complexity of the interactions between family, children and labor career, also from the gender perspective'. (Executive report, p. 30)

The confrontation of realities in Western European countries with experiences in countries in transition does not only enlarge the possible alternatives in social life, but the differing historical contexts produce rather different concepts. It takes some time before one realizes that the language used is missing common ground. An example happened during the first workshop on Migration. This workshop was held in Germany, November 2000. This first workshop gave inter alia a broad picture of migration processes in several countries, including the Baltic republics.

From the excellent report presented by our Estonian colleague, it emerged that a Belgian intuitive understanding of a 'migrant' and especially the demographic and cultural specificity of migrant groups is directed straight towards persons from developing countries. It never would come into mind to call a French, Dutch or German person a 'migrant'. Sure, in technical terms a permanent resident of one of these countries in Belgium (and there are a lot of them in the neighborhood of the European community headquarters!) is an immigrant. And in a process of demystification of the numbers of migrants in Belgium demographers always give the numbers of foreigners of the neighboring countries. In Estonia the situation is totally different. The concept of migrant encompasses all Russian persons who came into the country after WW2 and the late 1960's and 1970's. On the contrary, Russian persons who where living in Estonia before WW2 are member s of national minorities. 
So the statement "Extensive flows of international migration have resulted in the formation of a large population of foreign origin; its proportion is one of the highest in Europe" is to be understood in the political-historical context of this State.

The example shows that comparing countries on social phenomena asks for a thorough conceptual examination of the phenomena under study. Belgian and Estonian migrants should not be added (together with migrants of the other European countries) in order to get the overall picture of the stock of migrants in the new Europe. And the same is true for the concept of national minorities, there as well historical elements and political balances are mostly important to understand what are called a 'national minority' and what not. Again, the open and free discussion between scientific experts may open avenues to solve the conceptual problems.

The second workshop on migration was held in Helsinki, March 2002. The focus was set on the aspect of the integration and on integration policies. One of the invited speakers, Jonas Widgren (ICMPD) understood it to attract and reject his audience. His view on Europe was rather black and it seemed that even a group of scientists does blame the messenger of the bad news. His central point was to defend replacement migration and hence he recommended to open European doors as widely as possible. The argument was that the enlargement will not solve the aging of the total population, since the demographic patterns and prospects are even worse then those of the western and northern part. The executive report continues neutrally: 'According to the author, without replacement migration Europe will slowly but surely succumb into an archaic non-productive elderly landscape'. This last argument was rather shocking the public, including myself.

It is this surprising event, and my reflection on it, that I remember best. Even when you agree on the concepts used to describe and explain realities after checking them in a heterogeneous group of experts, this does not mean that every single story or forecast - even on an empirically sound basis - will be accepted. NIEPS was not only a network of scholars, it was a social group as well. After two years of rather intensive working together, a group culture has been build. Part of it is taboos on theories or hypotheses that are not politically correct at that time. This means that a network should critically assess its own openness for new ideas.

NIEPS has been indeed an open place of discussion, not less then 47 experts who are not a member of a participating institute shared their knowledge with the partners. The division of labor, with on the one hand institutes that organized workshops or technical meetings and on the other hand institutes that drafted the executive reports was respected until the end of the project. However there is an aspect of the positioning of each partner that is very important in the dynamics of a network, but is rather of an informal nature. Where the allocation of specific tasks and the composition are 
structural features of a network, the cultural equivalent is the respect for and the fostering of the specificity of the partners. Bringing together scholars from different cultural backgrounds is especially fruitful when the own academic, scientific and organizational characteristics are recognized.

The example to illustrate this point stems from the workshops on "Ageing, intergenerational solidarity, and age-specific vulnerabilities". The first workshop was held in Rome, April 2001; the second in The Hague, 2002 September. The technical meeting was held in Warsaw.

A high level of creativity, nearly artistic characterized the Italian organization of their workshop. In every single detail, the theme of the workshop was echoed. A leaflet with definitions of 'ageing' stemming from classic Latin 'De senectute' (Cicero); a video presentation of images of ageing in ancient and modern art underpinned the academic interests - again - in concepts and in conceptual clarification. This tool, which seems a luxury, apparently helps the memory to hold some of the ideas discussed during the seminar. Indeed, all four solicited papers dealt with conceptual issues.

Emily Grundy's elaboration of "vulnerable elderly people" is thought provoking. In her opinion they are 'those whose reserve capacity falls below the threshold needed to cope successfully with the challenges they face'. The interesting feature of this definition is that policy may work towards both sides: sustaining the reserve capacity and smoothing away the harsh aspects of the challenges. In the same session Jozef Pacolet was elaborating on the concept of 'dependency'. Gustavo de Santis launched a new concept of aging, including a new calculation of the threshold age for separating the young from the adults and the adults from the elderly. Finally, Jenny Gierveld reinforced the value of these creative suggestions by urging for a new content of "old age dependency ratio".

As far as I am concerned, the networking part of NIEPS was highly successful. Nevertheless three years are very short. It is remarkable that the European commission is installing dozens of networks all over Europe, even networks treating nearly the same issues. Notwithstanding the fact that the commission brings together coordinators once or twice during the project period, it seems to me that still more has to be done to develop a meta-networking system of experts dealing with the same issues. 


\section{Integrated population study, integrated population policy?}

The major objective of NIEPS was to work towards an integrated research design that should be useful to underpin integrated population policies.

In most workshops some links were defined with the issues of the other themes of the project. A few of them are unexpected and innovative.

From a macro point of view, several well-known links were documented and discussed. Aging in terms of the age structure of the population is directly linked to fertility patterns. Migration is increasingly discussed in relation to the question if it mitigates the negative consequences of aging in the short and the long run: not being a problem but a solution to a problem. Gender and work are linked to societal reactions to aging: the need for higher employment levels of all adults over a longer period of time in view of the sustainability of the current system of social solidarity. Family formation and fertility levels are linked to tools of combination of work and family life. These links suggest indeed that every single aspect be influenced by the other phenomena.

From a micro point of view as well, associations between the issues are paramount.

Family dynamics, gender and care issues in respect of children, chronically ill and older persons are aspects of the integration that are worthwhile to study. Thereby, we never should forget the diversity in the migrant population. Behavior, values and attitudes on fertility, gender, labor force involvement and care issues differ according to ethnic background but also according to the pattern of incorporation in the receiving country. The Helsinki seminar opened some pathways towards the analysis of the association between demographic patterns and modes of integration. Thereby, the salience of demographic indicators for measuring dynamics of social integration was demonstrated.

The care for vulnerable older persons depends on the availability of professionals and informal carers of younger generations. Smaller family groups, decrease of coresidence are factors that predict a higher need for professional care fromula, either at home or in residential settings. Perhaps newcomers can be directed towards these care jobs.

The executive reports of all workshops show many more linkages between the issues. Nevertheless, the focus of all six workshops was on a segmented view of the theme under study. The architecture of NIEPS apparently favoured more the segmented approach then partners intended to. Instead of focusing on the integrative issues, all partners were instrumental in broadening the specific theme. One of the reasons, 
positive in itself, is the fact that experts and public in each workshop stemmed from various academic disciplines and various professional backgrounds. Therefore, nearly every workshop concluded that much research work on the issue itself had to be done - especially in a comparative perspective.

In the NIEPS monograph, drafted by the consultants D. Avramov and R. Cliquet, the question of an integrated approach is developed further. The consultants indeed were presenting an inventory of items to be included in a common research tool during the last workshop in The Hague. As far as I can judge, it seemed to be too early to work towards a common integrated research project.

This means that NIEPS as a place of action was less succesful than NIEPS as an open place of discussion. To engage in a common project is much more complicated, it demands a high investment of human capital and it depends on external developments. The start of NIEPS coincided with the launching of the preparatory works on a new comparative survey. Several members were invited to participate in the design of this standardised instrument namely the 'Gender and Generations survey', co-ordinated by the Population Activities Unit of the UN European region. The terms of reference of this project are similar to the idea of an integrated approach. Therefore the need for still another project was less urgent. The second reason why the proposal of a new research project became marginal was that the continuity of the network was guaranteed, since most of the partners were members of the DIALOG- research program, co-ordinated by Prof. Ch. Hoehn, BIB.

Did NIEPS contribute to the development of a 'European Research Area'? There is no doubt about that. Researchers were stimulated to share their ideas with others; partners were invited to make comparisons between their own situation and the situation of other countries; discussions generated some consensus and some dissent positions; the output of the deliberations are published and a final publication is under way. But again, a much less tangible element - impossible to include in performance indicator systems - is the fact that the core members of the network became in some way good friends. We know that we can count on each other when needed. NIEPS not only contributed to the development of research capital, but to an increase in European social capital as well.

\section{References}

Commission of the European communities. 2000. Communication from the commission to the council, the European parliament, the economic and social committee and the committee of regions. Towards a European research area. Brussels COM, 6 . 